\title{
How to Reform Experiment Courses of Soil and Fertilizer Science
}

\author{
Yifei Liu, ${ }^{1, a}$, Xiaori Han ${ }^{1, b,{ }^{*}}$, Yan Wang ${ }^{1, b}$, Jinfeng Yang ${ }^{1, b}$, Qingwen Shi ${ }^{1, b}$, Qiaobo \\ Song ${ }^{1, b}$ and Hongfei Ren ${ }^{1, b}$ \\ ${ }^{1}$ Shenyang Agricultural University, Shenyang, 110161, China \\ aliuyifeiscience@163.com, bfeifan61@gmail.com \\ ${ }^{*}$ Corresponding author
}

Keywords: Soil and Fertilizer Science; Experiment Courses; Reform; Experience; Teaching.

\begin{abstract}
Soil and fertilizer are the essential natural resources and fundamental means in agriculture production. Soil and fertilizer science is a basic professional course for several majors such as agronomy, horticulture, plant protection and forestry. For purpose of integration of research and teaching, experiment courses shall be under relevant reform and adjustment in the colleges and universities, the natural juncture between scientific research and teaching. Soil and fertilizer science is a basic and professional course, whose self-contained experiment courses are considered as the key component in the relevant professional learning and teaching. An overall reform shall be carried out for the experiment courses of soil and fertilizer science, by way of taking such measurements as cutting back confirmatory experiments and adding exploratory experiments to stimulate the college students' interest in their majors and practical operation. Therefore, their change from passive absorption to active study shall boost their enthusiasm in science and technology innovation.
\end{abstract}

\section{Introduction}

Soil and fertilizer are the essential natural resources and fundamental means in agriculture production. Both are not only regarded as the energy sources for all the living creature including mankind, animals, plants and microorganism to maintain their life activities, but also as the hub of matter and energy circulation along the agriculture production links ${ }^{[1]}$. Soil and fertilizer science is a basic professional course for several majors such as agronomy, horticulture, plant protection and forestry. Its experiment teaching is the integral part in college and university education. As one of the key teaching links, it helps to fully implement education and training plans for agriculture and forestry talents, to improve the training quality as well. These courses not only serve the application and consolidation of theoretical knowledge from classrooms, but also serve the exploration, study and development in the new knowledge field. Thus students' ability in practical operation, ability to analyze problems and deal with problems shall be well trained during these experiment courses. Meanwhile they will be trained for their boldness in pioneering, for their courage in exploration, and for their seriousness and practicality in a scientific style. As what has been stressed in the Guidelines of the National Program for Medium- and Long-Term Educational Reform and Development (2010 2020) that college education shall support students' participation in scientific research, strengthen the steps in practical teaching, promote the interaction and integration between scientific research and teaching, and promote the combination among scientific research, teaching and creative talents cultivation. Therefore, the reforms in experiment courses of soil and fertilizer science are considered as one of the specific carriers for teaching and research integration in some relevant fields such as soil science, plant nutrition, fertilizer processing, plant physiology and biochemistry, along with molecular biology. The reforms hereby will work better in developing scientific innovation quality and inspiring scientific innovation enthusiasm for those students during experiment courses. 


\section{Existing Situation and Problems for Experiment Courses}

Existing Reform Situation Home and Abroad . Marschner's Mineral Nutrition of High Plants is the classical textbook worldwide for soil and fertilizer science (fertilizer science section). It is also the prescribed textbook for undergraduates in University of Hohenheim, Germany and University of Wisconsin, US, both of which are prestigious for their achievements in plant nutrition and fertilizer teaching and research. Most of the domestic textbook materials are from the translation of Edition I and II of Marschner's Mineral Nutrition of High Plants, and from the translation of Edition I of Mineral Nutrition of Field Crops written by Nand Kumar Fageria. However, new editions of Mineral Nutrition of Field Crops and Marschner's Mineral Nutrition of High Plants from 2010-2011 were officially published one after another. The textbook materials were substantially updated, and most of experiment courses were modified with focus on the efficient use of soil fertilizer resource, efficient nutrient absorption process and mechanism, in addition to research methodology for modern soil biology, plant nutrition molecular biology and ecology.

The teaching quality of Soil and Fertilizer Science (fertilizer science or referred as plant nutrition and fertilizer science) in these universities-China Agricultural University, Nanjing Agricultural University and Zhejiang University ranks top three as widely accepted nationwide, so they are deemed as the models in soil and fertilizer science teaching and research among agriculture colleges and universities in China. The experiment courses concerned have been properly adjusted in these three universities. In the world today, the interaction between teaching and research has been closer day by day for a big science advent, so as the natural juncture of teaching and agriculture scientific research, agricultural colleges and universities shall integrate the scientific research with undergraduate teaching for joint development. Teaching material and styles for soil and fertilizer science (fertilizer science or referred as plant nutrition and fertilizer science) in some other top colleges and universities are also duly adjusted to conform to the era development. For example, there are excellent courses given by Professor Feng Ke in Yangzhou University, excellent courses by Professor Xu Fangsen in Huazhong Agricultural University. These courses are reformed to be in closer touch with actual production, so they are more in line with the disciplinary development trends and full of more sense of times.

Existing Problems. At the moment, instructional experiment and style a dozen years ago are still in use for the experiment courses of soil and fertilizer science (fertilizer science section) in most of colleges and universities, including Shenyang Agricultural University, so they do not keep the pace with the time development, and the teaching materials for experiment courses are out of date with old fashion. There are only 9 credit hours for the experiment course teaching for soil fertilizer science (fertilizer science section), covering 3 experiments as merely 3 hours for each, so there is a serious lack of credit hours with poor support and efforts for scientific research ability training ${ }^{[2]}$.

Influenced by the idea of relying heavily on theoretical rather than practical teaching for quite some time, students are poor in their hands-on skills, and this is a universal fact in the current university teaching ${ }^{[3]}$. In order to deal with the problem that students are poor in their hands-on skills and in their comprehensive analysis ability, the traditional confirmatory experiment teaching pattern has to be broken and a new approach in experiment course reform has to be found out, for the old one is unable to meet up with demands nowadays ${ }^{[4]}$. Since the students keep on taking notes in the experiment class and pay more attention to finishing experiment reports as soon as possible without any independent thinking and practical operation, they are poor in problem analysis and experiment operation, rather inadequate of innovativity as a result. Experiment ability is regarded as a skill and taught as a form of "knowledge" under such a situation, where major teaching targets are not focused on the experiment ability training for students' independence and initiative, not focused on the preparation and development for consciousness and ability of innovation. Therefore, the most direct consequence is that students accumulate their experiment ability and innovation ability in such a "natural "way that they are incapable of applying their learning creatively ${ }^{[5]}$. 
In addition, the experiment courses are confirmatory equally, lack of novelty and sufficient depth, for instance, the content of soil alkali-hydrolyzable nitrogen (confirmatory), qualitative identification of mineral fertilizers (confirmatory), pictures and charters hung on the walls for nutrient deficiency symptom in major crops (confirmatory, whose answers are even marked out on some pictures and charters ). As a result, the existing experiment courses in the soil and fertilizer science (fertilizer science or referred as plant nutrition and fertilizer science) are unable to attain the goals of integration between research and teaching for academic education, and they are unable to meet the demands of ability building in knowledge use and innovation spirit cultivation for these college students.

\section{Teaching Reform and Practice Pathways for Experiment Courses in the Soil Fertilizer Science}

According to the development trend of the international college education, together with the existing situation of scientific and technological development in Chinese colleges and universities, the interaction between research and teaching for joint innovation shall be the only route to the innovation promotion for colleges and universities, as well as the only route to talent cultivation ${ }^{[6]}$. Based on such an idea, I have the following detailed suggestions on how to reform:

Education Idea Reform. The target adjustment in college courses reflects the shift in the development strategies and concepts for higher education, so reasonable changes or conversion in value orientation and function directivity of college courses are highly desired in terms of training quality and style for the college talents ${ }^{[7]}$. The traditional education is that teachers are to give lectures for students to accept, but I believe such a style shall merely limit the divergent thinking of those students. When teachers are giving instructions mechanically, students will have to be in passive absorption all the way, so they are not able to think independently or show more interest in experiments either. As the saying goes, "Interest is the best teacher." The education today shall not just serve transferring culture, knowledge and skills, nor just allow students to learn and accept what they are taught without their own ideas or innovation. The historic mission and social value special for Chinese modern education shall have to inspire students' desire for exploration in their lives, to develop their creative potential, to make their lives active, full of confidence and pioneering development, and full of ambition to struggle for the great rejuvenation of Chinese nation ${ }^{[8]}$. Hence, the education concept has to be changed, and it is much more important to inspire the students' interest and exploration desire. The teachers in soil fertilizer science during their teaching shall not only respect the students for their unique personality and study styles, but also instruct them to design their own study plans and styles, so as to help them master and apply the knowledge and technology in modern plant nutrition and fertilizer science, trying to enlighten and develop their innovation sense, spirit and ability as well ${ }^{[9]}$.

Teaching Method Reform . The new concept for modern higher education claims that teachers shall be the facilitators, organizers and instructors. Teachers and their students shall be equal and cooperative ${ }^{[9]}$. Teachers shall know the puzzlement and interest of their students in real time during their teaching; meanwhile they have to integrate the latest research achievements or some new achievements in other fields with their lectures. Additionally, they may allow more free time for students to have free discussion in class, when students' thinking breadth, depth may be under further development for more study interest. Moreover, multi-media teaching, as another good choice, is used to fully display teaching content to inspire students' interest. Various teaching methods such as projection, slide show, video, computers and the similar are used to offer written materials, maps, or pictures, so these visual forms of teaching aid will improve teaching efficiency.

Experiment Teaching Mode Reform. Comprehensive experiment teaching schemes shall be worked out and comprehensive instruction textbooks on experiments shall be compiled. All the students in soil fertilizer science experiment courses shall have to carefully collect samples, prepare samples, pre-treat samples and finish analysis and experiments of those samples in their own group. Some of the experiments may be finished in various ways, and a self-designed experiment is also 
required. This sort of teaching practice will be beneficial to the innovation training for those students. Prior to each experiment lesson, they are supposed to preview experiment instruction and understand experiment purposes, operation steps, method, principle and attentions. They are supposed to finish experiments independently with standard operation and correct results during each process. They are also supposed to observe and make records carefully. Upon the experiments are over, they are supposed to complete reports for their teachers to summarize accordingly, to demonstrate by operation and explain on the problems in experiments and experiment reports. All will prove to be helpful to the cultivation and consolidation of experiment operation skills. The details in our experiment courses include conducting field investigation for different types of soil, digging up a section, measuring soil fertility, identifying fertilizer processing equipment, and identifying true or counterfeit fertilizer and the similar ${ }^{[10]}$.

The confirmatory experiments are designed as comprehensive experiments, so that students have to design their own experiment schemes in advance, and they have to know the experiment fundamentals and steps, familiarize themselves with the application methods of the relevant instrument and appliance, as well as the regent preparation methods. With the help of comprehensive teaching of the experiment courses, some confirmatory experiments, as previously independent, are integrated as comprehensive experiments. All will enhance the understanding of theoretical knowledge and practical knowledge for the students, a favorable condition for their active learning, so that they will be motivated and trained for their enthusiasm in active learning, independent practice and self-innovation to improve experiment teaching results and efficiency ${ }^{[1]}$.

\section{Conclusion}

The reform in the experiment course teaching for soil fertilizer science will facilitate enhancing the practical ability, thinking ability and comprehensive ability to analyze problems for students, so that they will be able to acquire knowledge as a whole. "Exploration" is the intermediary between teaching and research, so if the idea that teaching is not compatible with research is abandoned, during the integration between teaching and research, students' interest in professional knowledge shall be aroused, and their awareness of the up-dated scientific and technological achievements shall be promoted as well ${ }^{[12]}$. The integration between teaching and research in colleges and universities will be the strategic choice for their medium and long-term development targets. This will be a key pathway for talent training, scientific research, social service, culture heritage and innovation ${ }^{[13]}$. By training in terms of experiments full of comprehensive designability and research exploration, students will be highly improved for their independent operational capability, ability of using knowledge, experiment design ability, research ability, innovation sense and every aspect, so that their scientific quality in literature review, experiment design, statistics, and academic writing will be well trained in efficient ways ${ }^{[14,15]}$. By deleting those confirmatory experiments and adding comprehensive experiments and research experiments, along with the networking of traditional courses, reform and practice are carried out for the experiment courses accordingly. All shall achieve the integration between the details and the international trends to enhance students' experiment skills, scientific innovation quality and to train them for their interest in their majors. All shall help to improve their ability to deal with real problems in production with what they have learned from plant nutrition and fertilizer science in a correlative way.

\section{Acknowledgment}

This research was financially supported by the Teaching Reform Project of Shenyang Agricultural University (Grant No. 2014-117), National Natural Science Foundation of China (Grant No. 31301842), China Postdoctoral Science Foundation (Grant No. 2012M510839 and 2014T70262), the Doctoral Scientific Fund Project of the Ministry of Education of China (Grant No. 20122103120011), Cultivation Plan for Youth Agricultural Science and Technology Innovative Talents of Liaoning 
Province (Grant No. 2014043), National Natural Science Initial Foundation of Shenyang Agricultural University (Grant No. 20112013), Postdoctoral Science Foundation of Shenyang Agricultural University (Grant No. 105110), Tianzhu mountain talents support program of SYAU and Peanut Nutrition and Fertilizer Program for China Agriculture Research System (Grant No. CARS-14).

\section{References}

[1] LIU Xiu-zhen, On reforming the teaching "Soil fertilizer science" course, Journal of Shanxi Agricultural University(Society Science Edition), vol.3, pp. 183-184, 2004.

[2] Broxton J M. Contrasting perspectives on the relationship between teaching and research, In Braxton JM(ed). Faculty teaching and research: is there a conflic. New Directions for Institutional Research, .vol.2, 1996.

[3] QIAN Yuan-huai, ZHANG Jing, and ZENG Qing-tao, Exploration on the reform of the genetics experimental teaching, Laboratory Research and Exploration, vol.3, pp. 18-19, 1998.

[4] P. Gajdanowicz, E. Michard, M. Sandmann, M. Rocha, L.G. Guedes Corrêa, S.J. Ramírez-Aguilar, J.L. Gomez-Porras, W. González, J.B. Thibaud and I. Dreyer, Potassium (K1) gradients serve as a mobile energy source in plant vascular tissues. Proceedings of the National Academy of Sciences of the United States of America (PNAS), vol.108, pp.864-869, 2010.

[5] ZHANG De-qing, ZHOU Cheng, YANG Qiu-bo, The comprehensive reform of experimental teaching and strengthen the training of innovation abilit, Heilongjiang Researches on Higher Education,vol.10, pp. 164-165, 2005.

[6] ZHOU Guang-li, MA Hai-quan, The fusion of science and education: reform and innovation of higher education concept, China Higher Education Research, vol.8, pp. 15-23, 2012.

[7] HAN Yan-lun, The humanistic orientation of college curriculum reform in foreign countries and in our university curriculum reform enlightenment, University Education Science, vol.2, pp. 83-86, 2005.

[8] YE Lan, The new exploration of the role of teachers and teacher development,Educational Science Publishing House, Beijing, 2001.

[9] XU Wei-hong, On teaching metghodology for the course of plant nutrition and fertilizer science and its practice, Journal of Southwest Agricultural University(Social Science Edition), vol.4, pp. 173-175, 2006.

[10]LIU Yi-fei, HAN Xiao-ri, The teaching reflection of soil and fertilizer science course for horticultural undergraduate, China Science and Technology Information, vol.17, pp. 146-147, 2012.

[11]MO Zhi-xin, ZHENG De-ming, ZHI Jin-hu, Preliminary probe into comprehensive teaching for "Plant nutrition and fertilizer science experiment", Journal of Tarim University, vol.21, pp. 98-101, 2009.

[12]Clark B R. The modern integration of research activities with learning and teaching [ $\mathrm{J}]$. Journal of Higher Education, 1997, 68(03): 242.

[13] YANG Wen-qiang, MA Yun-kuo, LI Wei, The fusion of science and education: the university personnel training strategy choice, Chinese University Science \& Technology, vol.8, pp. 49-51, 2013. 
[14]XIA Fan, YU Zhi-he, The reform of microbiology experimental teaching to cultivate students' innovation ability, Microbiology, vol.5, pp. 1023-1026, 2007.

[15]LIU Yi-fei, QI Hong-yan, BAI Chun-ming, QI Ming-fang, XU Chuan-qiang, HAO Jing-hong, LI Yan, LI Tian-lai. Grafting helps improve photosynthesis and carbohydrate metabolism in leaves of muskmelon. International Journal of Biological Sciences, vol.7, pp. 1161-1170, 2011. 